\title{
Presença e morte: o carácter efémero das artes do corpo
}

\author{
Pedro Bessa
}

Departamento de Comunicação e Arte, Universidade de Aveiro, Portugal
[ID+] Instituto de Investigação em Design, Media e Cultura, Portugal
Mariana Assunção Quintes dos Santos
Departamento de Comunicação e Arte, Universidade de Aveiro, Portugal

\begin{abstract}
This paper aims to reflect on a hypothetical threshold-space between contemporary dance and performance art, questioning at the same time the prevalence of too strict a boundary between them. To this end, a range of works involving hybridization of artistic languages were selected and analyzed, from Signals (1970) by American dancer and choreographer Merce Cunningham to Café Müller (1978) by German choreographer Pina Bausch. Both dance and performance art are ephemeral arts or, according to the classical system, arts of time as opposed to the arts of space - painting, sculpture and architecture. They have also been called allographic arts, performative arts or, perhaps more specifically, arts of the body (Ribeiro, 1997). Unlike traditional fine arts, which materialize in a physical object other than the body, unlike video-art and cinema, arts without originals, mediated by the process of "technical reproducibility" (Benjamin, 1992), performative arts require the presence of a human body - and the duration of the present - as a fundamental instrument for their realization. In that sense, the paper also focuses on the ephemerality factor associated with dance and performing arts, and the consequent devaluation these have suffered vis-à-vis other artistic practices, considered to be academic and socially more significant.
\end{abstract}

Keywords: allographic, contemporary dance, ephemeral, hybridization, performance art.

\section{Introdução}

Dança, teatro, performance art são artes do efémero. Artes do tempo, como eram chamadas por oposição às artes do espaço - pintura, escultura e arquitetura - nos sistemas clássicos (Huisman,1984, p. 113). Por serem linguagens efémeras, acabam por nem sempre ter a mesma valorização que as tradicionais artes do espaço, como a pintura, a arquitectura e as artes plásticas, possuem. Isso decorre, em parte, da reconhecida dificuldade em historiar a produção das artes performativas "e problematizar este género para lá da contemporaneidade do acontecimento". (Ribeiro, 1997, p.19). Acresce o fato de a dança possuir também menor espaço de reflexão crítica (Setenta, 2011, p.192) ou, pelo menos, este se encontrar menos mediatizado.

$\mathrm{Na}$ verdade, como lembra António Pinto Ribeiro (1997, p.21):
As artes do corpo foram, até ao modernismo do século $\mathrm{XX}$, tomadas como práticas recreativas desprovidas de qualquer validade de conhecimento, tidas como actividades de natureza mundana com propósitos meramente de intermezzos... [ou] destinadas a intercalar outras práticas artísticas que, ainda que utilizassem o corpo, o faziam tomando-o como um elemento secundário, em última estância possibilitador de tornar presente os textos dramáticos ou as músicas, estas sim, práticas que subsistiam por terem poéticas antigas.

Inclusive hoje, entre os/as bailarinos/performers mantem-se vivo o sentimento de que a dança é desvalorizada enquanto prática artística (Santos, 2019). Talvez pelo facto de o acto de dançar ser tão universal e comum, uma forma de manifestação cultural popular em qualquer sociedade, mas também certamente por seu processo de criação ser tão diferenciado do de outras artes. Na dança recorremos principalmente ao corpo e ao movimento para investigar e criar, e não possuímos um guião claro e escrito do que acontecerá em cena - ao contrário do que sucede, por exemplo, no teatro (onde a peça ou texto dramático de um Shakespeare possui um valor literário intrínseco, suficiente para seu reconhecimento como autor maior da literatura mundial), ou no cinema ou na música (partitura).

Por outro lado, à pintura, à escultura, até mesmo ao cinema, "resta sempre a possibilidade da convocação material da obra ou da sua reprodução... para estes casos é possível constituir um arquivo do produto artístico" (Ribeiro, 1997, p.18), algo impossível nas artes performativas que se sustentam no corpo como suporte /medium artístico. A performance do/a bailarino/a em palco não resulta num produto final estabilizado, num objeto físico de que o público possa disfrutar, mas também levar para casa ou revisitar quantas vezes queira no espaço de um museu.

Contudo, a efemeridade é de fato uma característica somente das artes do tempo? Só as artes do espaço são perenes, porque fisicamente subsistentes? Um espectador de uma apresentação de dança ou de performance art volta para casa somente com a lembrança do que aconteceu no espetáculo. Mas isso também não sucede com o mesmo espectador que vê uma exposição numa galeria de arte e volta para casa somente com a memória do que viu exposto? Os estudiosos reconhecem hoje que a dimensão temporal não é estranha à percepção da pintura e escultura (Carchia e D'Angelo, 2003, p.40), já para não falar da vídeo-instalação.

O presente trabalho começa por interrogar a tênue linha de fronteira/osmose existente entre dança 
contemporânea e performance art com o objetivo de melhor as conhecer, compreender e eventualmente transcender. São assim analisados alguns exemplos emblemáticos de hibridação nas práticas artísticas contemporâneas, com destaque para o trabalho dos/ as coreógrafos/as Merce Cunningham, Trisha Brown e Pina Bausch, entre outros.

Finalmente, propõe-se uma reflexão sobre o carácter efêmero das artes performativas ou, mais especificamente, artes do corpo (Ribeiro 1997, pp. 19, 102), relevando o elemento da presença, do momento irrepetível, visando contribuir para o reconhecimento da dança enquanto prática artística.

\section{Dança, performance art, artes do corpo e artes performativas}

De acordo com o dicionário Houaiss, dança é um "conjunto organizado de movimentos ritmados do corpo, acompanhados por música". Já performance (1), segundo o mesmo dicionário, designa uma "atividade artística inspirada em formas de arte diversas, esp. o teatro". Também o dicionário Priberam da Língua Portuguesa, reforçando esse carácter híbrido da performance art, a define como "manifestação artística que pode combinar várias formas de expressão."

António Pinto Ribeiro propõe que a dança, a performance art e o teatro-físico fossem agrupadas num novo género, designado artes do corpo, acrescentando que "todas as artes do corpo são artes performativas. Estão condicionadas pela necessidade da performance dos intérpretes das suas obras." (Ribeiro, 1997, p.103).

Porém, e ainda que a performance art se assemelhe ao teatro, já que "a performance é antes de tudo uma expressão cênica” (Cohen, 2002, p.28), há uma diferença crucial que separa essas duas linguagens. Como refere Goldberg (2012, p. 9), “ao contrário do que se verifica na tradição teatral, o performer é o artista, quase nunca uma personagem, como acontece com os atores, e o conteúdo raramente segue um enredo ou uma narrativa nos moldes tradicionais.". Diferentemente do teatro, onde texto e diálogo desempenham papel fundamental, são a base para tudo o resto, a dança e performance art afirmam-se pela presença do artista-performer enquanto obra em si. O corpo e seus movimentos, seu fazer-dizer (Setenta, 2011) constituem o próprio medium da obra.

Como diz Schechner (2013, p.1), "performances são ações". Indo um pouco mais longe,

Fischer-Lichte (2019, p.25) considera mesmo que na performance art "deixa de haver uma obra de arte independente do criador e do receptor; em vez disso lidamos com um acontecimento em que todos estão envolvidos". Uma performance de Marina Abramovic resiste "a uma estética hermenêutica que aspira a compreender a obra de arte" (ibid. p.18); perceber as acções da artista é menos importante do que a sua experienciação in loco, quer pelos espectadores quer pela própria.
Entretanto, segundo Goldberg (2012, p. 10), “devido à sua natureza, a performance dificulta uma definição fácil ou exacta que transcenda a simples afirmação de que se trata de uma arte feita ao vivo pelos artistas." Na mesma linha de pensamento, Fabião (2011, p.191) acredita que performance art seja indefinível. E aponta como características gerais:

A ênfase no corpo como tema, matéria e meio...; a desconstrução da representação e a valorização do corpo-em-experiência; a hibridação de gêneros (fusão ampla, geral e irrestrita de materiais e procedimentos que caracteriza não apenas a [arte-]performance, mas muita arte contemporânea); o investimento na irrepetibilidade e na irreprodutibilidade...; o elogio ao precário, ao passageiro, ao imprevisível... (ibid.).

Porém, quantas destas características não poderiam aplicar-se igualmente à dança contemporânea? Assim, para Siqueira (2006) a grande marca desta última é a diversidade, seja de estilos, géneros, ações. Já para Lepecki (2011), é a experimentação o que define a dança contemporânea, sendo esta sua principal característica. Para outros autores, as características da dança contemporânea estão na relação intrínseca entre movimento e liberdade:

Autonomous movement of the body opened new potentials of human experience and relationships (...) They provided the possibility of a new aesthetic experience, because of their intrinsic relationship between movement and freedom, which was presupposed in almost every attempt at movement reform. (Kunst, 2011, p.49)

O próprio Rudolf von Laban (1879 -1958), considerado o pai do expressionismo e uma das principais figuras da dança moderna, já não partia do estudo da dança, mas daquilo a que chamava "arte do movimento". Na sua tentativa de criar uma notação (espécie de "partitura" da dança) começa por estudar os movimentos humanos, estabelecendo oito ações básicas do movimento (Laban, 1978), assim reformulando o entendimento do que era conhecido como dança, com passos e técnicas pré-estabelecidas, e.g. no ballet clássico.

Como referido acima, uma das principais características da performance art é o uso do corpo como suporte artístico. Como diz Ciotti (2011, p. 29), "na performance, o corpo humano é sujeito e força motriz da linguagem cênica". No mesmo sentido, Cohen (2002, p. 30) aproxima-a da body art, tanto a nível do conceito quanto da prática.

Mas também na área da dança, Jussara Setenta (2011, p.192) acredita que esta funciona como "uma espécie de fala do corpo". E assim como acontece com o ato de falar propriamente dito, também o corpo busca formas diferentes de falar. Setenta define essa modalidade de fala como um "fazer-dizer", construído no e pelo corpo. Desse modo, podemos, prolongando a analogia, considerar a coreografia como sendo a "fala" da dança, enquanto as diferentes maneiras de se falar seriam os passos. 
Pensar ambas, dança e performance, como um fazer que é dizer e, onde, dança, performance e política coexistam aciona outros modos de agir artisticamente, capazes de discutir, com o seu fazer, qual o 'lugar' destas ações artísticas na sociedade atual. (...) No campo da dança, um encolhimento crítico reflexivo o destaca do campo da performance. Por conta disso, existem ênfases em discussão para o fazer-dizer da dança. Entretanto, as questões e considerações em movimento transbordam o campo da dança e borram-se nas observações em performance. (Setenta, 2011, pp. 191-192).

Podemos então concluir, provisoriamente, por uma proximidade entre as práticas da dança e da performance art, ambas centradas no corpo, sendo ainda de destacar a existência de uma menor reflexão crítica na área da dança, talvez porque ainda incipiente enquanto área acadêmica.

\section{Hibridização na arte contemporânea: o diluir de fronteiras}

Como se referiu acima, práticas artísticas contemporâneas implicam quase sempre algum grau de hibridização e interdisciplinaridade. Todavia, apesar de agregar outras linguagens artísticas e ser reconhecida pelo seu hibridismo, a performance art, a partir da década de 1970, é considerada um "meio de expressão artística independente" (Goldberg, 2012, p. 7). Ou seja, desde essa época que o termo performance é reconhecido como um tipo de linguagem artística, assim como a dança, o teatro, a pintura, mesmo sendo interdisciplinar. De qualquer forma, como hoje a dança contemporânea apresenta diversas vertentes e estilos, já que com ela, a dança se "libertou" do palco italiano e das técnicas rígidas, facilmente poderia ser aproximada à performance art.

Ora, se a performance art se utiliza do corpo para se expressar e a dança se caracteriza pelo movimento do corpo, poderíamos quase considerar que a performance art também seria dança. Na verdade, muitos bailarinos - de que Merce Cunningham é apenas o exemplo mais conhecido - participaram em eventos de âmbito performativo, ou criaram suas próprias performances. Como seguem os quatro exemplos a seguir:

Pina Bausch, coreógrafa alemã pertencente ao expressionismo alemão e fundadora do conceito de Dança-Teatro, tem como sua obra mais emblemática Café Müller (1978). Esta obra é um bom exemplo de uma dança que fugiu dos padrões clássicos do ballet. Tinha uma quantidade enorme de cadeiras em cena atrapalhando a locomoção dos bailarinos, propositadamente -- um dos integrantes da cena era responsável por tirar as cadeiras da frente dos bailarinos que se deslocavam de olhos fechados para não baterem - figurinos simples como de um dia normal, além de os movimentos não serem virtuosos e propensos à beleza.

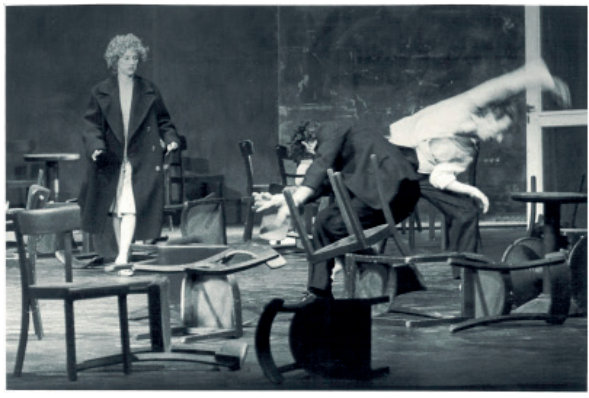

Figura 1: Café Müller (1978).

Fonte: http://www.pina-bausch.de/en/works/complete-works/ show/cafe-mueller/

Robert Wilson, encenador norte-americano, trouxe para a cena artística a obra Einstein on the Beach (1976), considerada uma das mais importantes produções do século $X X$ na área da música e artes do palco. Com texto e música de Phillip Glass, essa peça é composta por dança, teatro e música, podendo ser considerada uma ópera, mas que foge dos padrões tradicionais, como por exemplo, não possuir uma narrativa. De acordo com Robert Wilson, o espectador não precisa entender nada, pode se perder na peça. Com duração aproximada de cinco horas sem intervalos, o público poderia se sentir livre para sair e voltar quando quisesse. "Einstein on the Beach was revolutionary when first performed and is now considered one of the most remarkable performance works of our time." (Wilson, para. 3)

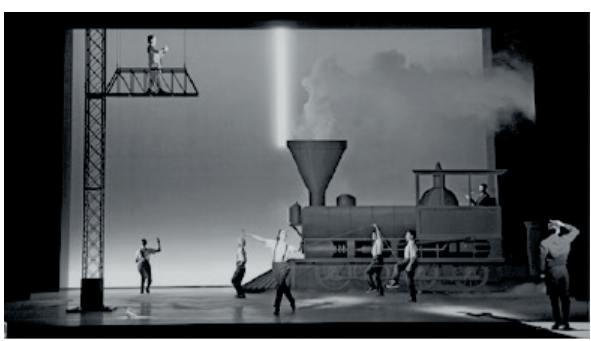

Figura 2 - Einstein on the beach (2012). Fonte: http://www. robertwilson.com/einstein-on-the-beach/

Trisha Brown, coreógrafa e bailarina norte-americana, foi inovadora no campo de investigação da dança, trazendo para a cena o cotidiano, a improvisação e o movimento natural. A obra Floor of the Forest (1970) tinha como descrição "Duas pessoas se vestiram e se despiram" e refletia de facto o ato de se vestir e despir. Foi construída uma rede de cordas com roupas penduradas e os bailarinos dançavam entre elas. Com uma ação do dia-a-dia, Trisha Brown estabeleceu uma outra relação à ação, pois a cena acontecia na horizontal e não na vertical como normalmente. Outra característica da coreógrafa é que ela primava por apresentações em museus, galerias e espaços abertos, fugindo dos palcos tradicionais. 


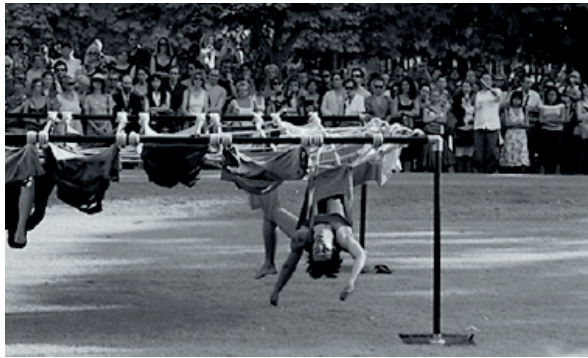

Figura 3 - Floor of the forest (2008). Fonte: http://www. trishabrowncompany.org/repertory/floor-of-the-forest. html?ctx=title

Merce Cunningham, coreógrafo norte-americano com diversas facetas artísticas, procurava acrescentar às suas coreografias outras linguagens e até, em algumas delas, tecnologia. Junto com seu parceiro John Cage, musicólogo, eles moldaram sua maneira de fazer arte, uma arte que valorizava o processo em vez do produto final e explorava os elementos fornecidos pelo acaso.

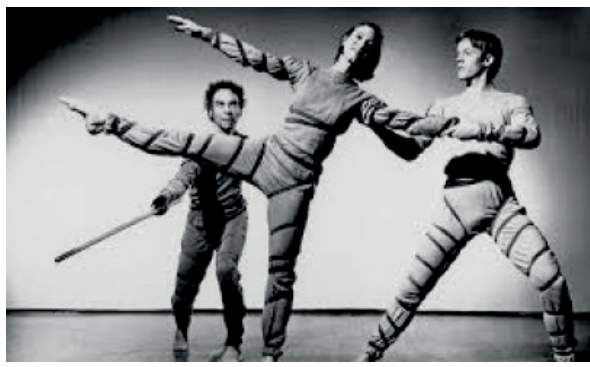

Figura 4 - Signals (1970). Fonte: https://dancecapsules. mercecunningham.org/overview.cfm?capid=46102

Signals (1970) foi uma de suas obras diferentes, cada apresentação tinha uma ordem coreográfica e mudava de acordo com o desempenho dos intérpretes. Assim como a música, cada espetáculo era uma composição diferente. Suas obras só se juntariam em dias de apresentação, ou seja, as criações coreográficas e musicais eram feitas de modo independente e os bailarinos só conheceriam a música na hora de entrar em cena. Essa característica muda de uma certa forma o entendimento de um espetáculo de dança tradicional, onde os passos executados correspondem aos compassos musicais.

Por assim dizer, depois de algumas definições, tanto de performance art quanto de dança e dança contemporânea, e exemplos de algumas obras-chave e coreógrafos, percebemos que o entrelaçar entre a dança contemporânea e a performance art é real e vai muito mais além do uso do corpo em cena, perpassa pelas diversas possibilidades de fazer arte, pela sua interdisciplinaridade mútua, o caráter experimental e livre de regras.

\section{O carácter efémero das artes do corpo}

La musica non è da essere chiamata altro, che sorella della pittura...ma la pittura eceelle e signoreggia la musica, perch' essa non more imediate dopo la sua creatione, come fa la sventurata musica, anzi resta in essere e ti si dimostra in vita quel, che in fatto è una sola superfitie... (2)

Leonardo da Vinci, Trattato della pittura, 29.

A frase de Leonardo da Vinci, citada em epígrafe, é ilustrativa de uma tendência que vem pelo menos desde o Renascimento em valorizar as "artes do desenho", i.e. pintura, escultura e arquitetura (3), ou artes do espaço, em relação às artes do tempo: teatro, música e dança.

A oposição entre artes do tempo e do espaço desenvolveu-se historicamente no Ocidente entre os séculos XVII e XVIII e, a partir de determinado momento, teve como principais expoentes a pintura e a poesia, duas artes que utilizam meios completamente diferentes, senão mesmo opostos:

A primeira serve-se de 'figuras e cores no espaço', a segunda, de 'sons articulados no tempo'. O âmbito próprio do poeta é a 'sucessão temporal', enquanto o do pintor é o espaço... A pintura pode apenas sugerir as acções através da atitude dos corpos, devendo por isso tratar de escolher o momento mais significativo, enquanto a poesia pode representar os corpos, mas só através das acções: as descrições resultam débeis e pouco eficazes... porque o poeta 'pode mostrar os elementos da beleza apenas um após outro'. (Carchia e D'Angelo, 2003, p.40)

Segundo Huisman (1984, p. 113), os sistemas clássicos organizavam-se em torno de uma dicotomia entre artes do espaço e artes do tempo: três artes plásticas (pintura, escultura, arquitetura) opõem-se a três artes rítmicas (dança, música e poesia), num sistema coroado pela chamada "sétima arte", o cinema. Apesar de incompleta (sem lugar para o teatro ou a literatura em prosa, já para não falar de artes ditas "menores" como o vitral ou a cerâmica) e pouco satisfatória, esta classificação mantém-se, com ocasionais melhoramentos ou adaptações, quase inalterada até às vanguardas artísticas do séc. XX.

Apenas os desenvolvimentos ocorridos na contemporaneidade, e.g. na área das artes visuais superando os limites dos media tradicionais e consignando novas formas artísticas como a instalação e a performance, vieram pôr em causa quaisquer tentativas de divisão rígida. Por outro lado, também a psicologia e teoria da recepção demonstraram que "a dimensão temporal não é de facto estranha à percepção das imagens" (Carchia e D'Angelo, 2003, p.40). Nas palavras de Huisman (1984, pp. 112-113) "o tempo é essencial na arquitectura, na pintura, e seria vão negar o carácter temporal que se prende à majestade dos templos gregos, à rapidez grácil da escultura gótica flamejante". 
Um dos autores que primeiro assinalou o erro de uma distinção a priori entre espaço e tempo foi $\mathrm{E}$. Gombrich (1964, p. 293), ao alertar para o modo como o problema do tempo nas artes plásticas tinha vindo a ser negligenciado.

De acordo com a teoria clássica, um pintor antes de pintar, observa o espaço e escolhe um determinado momento para passar o que acabou de presenciar para a tela. Mas não pode ser qualquer momento, a escolha certa é crucial. O pintor deve pintar um momento em que quem olhe para a tela consiga imaginar um antes e um depois. Para representar o movimento, ou a sucessão no tempo, a solução será combinar dois momentos como "acontecendo num mesmo e único instante" (ibid., p. 294), i.e. representá-los numa única imagem.

$\mathrm{Na}$ teoria estética do século XVIII, autores com Lessing ou o conde de Shaftesbury relevam a importância de uma correta escolha desse momento "pregnante", embora Shaftesbury (cit. por Gombrich, 1964, p.294) admita que esse modelo da ação instantânea frequentemente fracassa: nalgumas representações do mito clássico Diana e Actéon, a deusa é vista lançando água em Actéon, cujas hastes já estão crescendo, embora ele ainda não esteja molhado.

De Leonardo à invenção da Fotografia, passando pelos paisagistas do século XIX, deparamo-nos como um mesmo desejo de capturar o momento efémero, de conseguir parar o tempo de modo a criar uma imagem para a eternidade.

Determinadas imagens ou composições visuais são habitualmente entendidas como 'estáticas' e outras como instáveis ou 'dinâmicas'. Por que razão, pergunta Gombrich (1964, p.305), entre duas reproduções fotográficas do Discóbolo, de Miron (cópia romana de bronze, séc. II d.C.), sentimos uma maior impressão de movimento e velocidade na vista lateral? A resposta está na forma como percepcionamos. Ver é buscar um sentido: à medida que olhamos esse esforço precede-nos, procurando completar as formas do que vemos, exatamente do mesmo modo que, quando escutamos uma frase musical tendemos já, por antecipação, a completá-la no ouvido.

O tempo está, pois, presente até mesmo na forma como vemos uma escultura ou um quadro. $O$ que não impediu que, devido à sugestão de permanência, de eternidade que as artes do espaço oferecem elas sempre encontraram especial acolhimento junto dos mecenas da época clássica -- príncipes da igreja, corte, aristocracia e alta burguesia.

Um sentimento tem as suas raízes no Renascimento italiano, senão mesmo em tempos mais recuados. Ars longa, vita brevis (4): porque sobrevive ao tempo, a arte pode trazer-nos a imortalidade. De início, este recurso estava reservado aos poetas, cujas versos e canções imortalizavam os heróis e guerreiros caídos (5). Mas a partir da Renascença caberá especialmente às artes plásticas, à pintura e à escultura monumental essa tarefa de preservar a fama dos homens ilustres para a posteridade. Como escreve o pintor e humanista português Francisco de Holanda (1983, p. 246), a pintura "deixa dos presentes para os que hão de vir depois d'elles". Já Castiglione (1987, p.98) prefere a escultura. Esta arte tem "maior dignidade" do que a pintura, porque as estátuas "duram mais tempo".

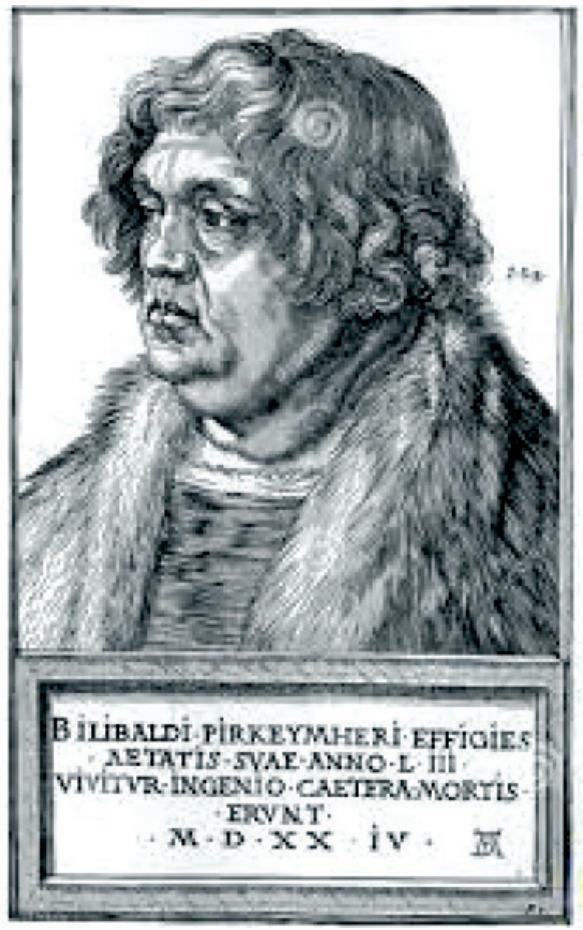

Figura 5 - Albrecht Dürer, Retrato de Willibald Pirckheimer, 1524 , gravura. A inscrição latina, Vivitur ingenio, caetera mortis erunt traduz-se como "Vivemos através do génio [ou espírito], o resto pertencerá à morte." Fonte: https://www.europeana. eu/portal/pt/record/2022703/oai_euromuseos_mcu_es_ euromuseos_MLGM_00556.html

"Oh, maravilhosa ciência que consegue preservar a beleza transitória dos mortais e dotá-la de uma permanência maior do que a das obras da Natureza pois estas últimas estão sujeitas à mudança contínua do tempo", escreveu Leonardo da Vinci referindo-se à pintura (cit. por Richter, 1980, p.197). Poderá parecer contraditório que o mesmo Leonardo que, em Milão, organizou bailes de máscaras e efémeros festivais de corte (6) argumente depois acerca da superioridade da pintura. Mas a consciência dessa fraqueza congénita a todas as artes efémeras, desse "morrer imediatamente após ter nascido" (Richter, 1980, p.197) é algo que, paulatinamente, se acabará por impor nos séculos seguintes.

\section{A imediatez da presença}

Dado que a dança não produz artefactos que sobrevivam aos séculos (pinturas, desenhos, monumentos arquitetónicos), nem deixa para trás 
documentos escritos (partituras, textos dramáticos) temos até dificuldade em conhecer a sua história de modo adequado. Sabemos, por exemplo, que o teatro grego teve origem no ditirambo, uma espécie de dança com cânticos em honra do deus Dioniso, mas isto apenas porque Aristóteles o refere de passagem na sua Poética (1992, p.108).

Tal como a tradicional pintura a óleo, também as origens do balé /dança clássica remontam às cortes do Renascimento italiano dos séculos XV e XVI. Mestres de dança ensinavam os passos a uma clientela de sofisticados aristocratas e burgueses endinheirados que a praticavam como forma de entretimento social e símbolo de estatuto. Estes mestres ou professores de dança não eram considerados artistas no mesmo sentido que os pintores e arquitetos que as cortes italianas já então disputavam entre si. O seu estatuto social seria mais parecido com o dos mestres de esgrima ou dos músicos profissionais (instrumentistas). Levada para França por Catarina de Médicis, essa dança aristocrática, extremamente formalizada atingirá aí o seu desenvolvimento máximo. Na segunda metade do século XVII, com a fundação da Académie Royale de Danse por Luís XIV, surge então a primeira companhia de balé, na Ópera de Paris (Bourcier, 2006), iniciando-se um lento processo de reconhecimento artístico.

Hoje somos capazes de compreender que "as artes plásticas comportam um tempo igualmente tão essencial como as artes ditas do tempo... e as artes rítmicas são tão espaciais como as artes ditas do espaço." (Huisman, 1984, p. 113). No entanto, ainda sentimos, por assim dizer, toda essa herança histórica de valorização das artes do espaço, i.e. artes plásticas e monumentais. Uma dança não tem como ser comprada e ser levada para casa, ela é feita para ser apreciada, tem um início, um meio e um fim, E o mesmo sucede com as restantes artes do corpo: teatro, arte de acção, performance art.

A "desafortunada música", dizia Leonardo, morre mal acabou de nascer. $\mathrm{E}$ o mesmo poderia ser dito do teatro, da dança ou da performance art, mas isso apenas acontece porque são artes alográficas (Ribeiro, 1997, p.102) , i.e. em que a partitura, o texto ou a notação nada perdem pelo facto de serem sucessivamente interpretados. Pelo contrário, essa "fraquesa" - pois dela depende sua existência - é simultaneamente aquilo que nos enriquece, facultando-nos um reportório de versões.

Foi somente a partir da documentação /arquivo das artes do tempo, com a evolução dos equipamentos audiovisuais, que as obras puderam fazer registos de suas apresentações, demonstrando uma certa tangibilidade ao ideal do ars longa, vita brevis, da arte perene. Entretanto, o registo de uma obra efêmera não subtrai toda a efemeridade que ela apresenta, pois a filmagem por mais que mostre a obra do início ao fim não capta a experiência sensorial de ver ao vivo (Rein, 2011; Miller, 1986). Como refere Ribeiro (1997, p.19), as soluções "de registo videográfico são... falaciosas, na medida em que os registos dependem sempre de um ponto de vista técnico e exterior à obra e, em cada momento de reprodução da mesma, exclusivo."

Há já quase um século, numa visão talvez demasiado optimista do potencial emancipador das técnicas de reprodução em massa, Walter Benjamin propôs uma arte sem originais. Segundo ele, os progressos ocorridos com a fotografia e, muito especialmente, o cinema, permitiram revolucionar a futura relação entre arte e público. Libertada da sua "aura" de peça única, de objeto de culto prezo a um local e com uma história que era indissociável das "diferentes relações de propriedade de que foi objecto" (Benjamin (1996, p.77), a obra de arte emancipa-se. E a sua fruição transita do espaço privado - onde apenas era destinada uns para poucos - para a esfera pública.

E contudo, os espectáculos de teatro, arte-acção, dança e performance art que, a partir da década de 1970, colocam a ênfase na corporeidade, podem em parte ser interpretados como uma reacção à crescente reprodutibilidade tecnológica / mediatização da cultura. Fischer-Lichte chamou recentemente a atenção para a tendência de abstracção progressiva, que ocorre na modernidade, um processo

\begin{abstract}
...no qual a distância do ser humano relativamente ao seu próprio corpo e relativamente aos corpos dos outros... é cada vez maior. No século XX, este processo alcançou o zénite com a invenção e a difusão dos novos media: os corpos volatilizam-se em representações mediáticas que, apesar da aparente proximidade, se entrincheiram e se subtraem a todo o tipo de contacto. (Fischer-Lichte, 2019, p.215)
\end{abstract}

Diferentemente do que sucede no cinema, videoarte, ou ambientes digitais "imersivos", que assentam na reprodutibilidade técnica, na dança contemporânea e na performance art o corpo do performer "opõe-se, na sua unicidade e no seu caráter de acontecimento às imagens reproduzidas à exaustão pelos media tecnológicos" (ibid., p.216), remetendo para uma "estética da presença" (ibid., p.235). Como lembra Ribeiro (1997, p.102), estas artes

\begin{abstract}
...só de realizam de facto, na imediatez da presença, porque qualquer reprodutividade das mesmas relato, vídeo, disco ou outro registo audiovisual - as torna incompletas, inacabadas, porque, no momento do registo se lhes retira a presença e a energia corpórea especifica de um ...momento irrepetível, que é substituído pela representação e um registo tomado por um determinado ponto de vista.
\end{abstract}

Nas gravações de uma performance, bem como de uma ópera ou de um bailado, o vídeo é feito e montado pelos olhos do cinegrafista e é o posicionamento da câmera que definirá o que o espectador irá ver. Dessa forma, só será viável assistir de um determinado ângulo (que, mesmo quando se altera, sempre permanece fixo), sem possibilidade de perceber o ambiente amplamente e captar a reação do público durante a performance dos artistas. Toda a complexidade e experiência sensitiva que envolve a peça não estará na filmagem. 


\section{Conclusão}

Como foi apontado, o enaltecimento - por vezes, o autoelogio - das artes do desenho / artes visuais ocorreu a partir do Renascimento com a consagração de grandes vultos da pintura e escultura, muitos deles ainda em vida - como aconteceu como o próprio Leonardo. Entretanto, se pararmos para pensar, a dança enquanto arte maior, i.e. actividade passível de estudo-aprendizagem numa academia, apenas foi reconhecida na segunda metade do século XVII, com o desenvolvimento do que conhecemos hoje como balé clássico.

A situação parece mudar de forma radical no século $\mathrm{XX}$. Em especial os dois períodos de pós-guerra mundial são marcados por experimentações de toda a índole, novas formas de fazer arte, novas linguagens que surgem, novas abordagens. Tudo parece possível em arte. É nesse contexto que a dança contemporânea e a performance art, inserindo-se num movimento mais vasto de manifestações artísticas, confrontam a sociedade, usam e abusam do fazer artístico, extrapolam os limites e põem em causa a aura, o valor de culto associado à obra de arte tradicional, enquanto objecto único e raro, destinado a uma elite.

Nesse sentido, foi observado que tanto a dança contemporânea como a performance art podem ser categorizadas como linguagens artísticas sem técnicas predefinidas, que trabalham com a transdisciplinaridade, que são obras livres e que abordam frequentemente 0 conceito de corpo enquanto protagonista da obra. A partir dos exemplos de Merce Cunningham, Pina Bausch, Robert Wilson, Trisha Brown, ficou também claro que a fronteira entre aquilo que é dança contemporânea, performance art, ou outra linguagem é hoje impossível de definir.

E no entanto, apesar de todo o experimentalismo e liberdade presentes na contemporaneidade, superando os limites dos media tradicionais e criando novas formas artísticas, a dança contemporânea e a performance art se mantêm até hoje como exemplos de uma arte que "morre no momento". Uma arte que não é perene, no sentido em que não se materializa num suporte físico, e onde mesmo o registo através de meios videográficos e digitais é, para além de deficitário, impotente para conservá-la enquanto produto artístico. O carácter intrinsecamente efémero destas formas artísticas acarreta consigo uma frequente desvalorização relativamente as outras linguagens.

Compreende-se assim que, mesmo com toda a trajetória de progresso e busca pela valorização das artes do corpo, muito ainda necessita ser feito para que estas vejam sua importância plenamente reconhecida nos meios culturais e não só. Para que isso possa acontecer são necessários mais estudos que, à semelhança do presente trabalho, ajudem a trazer a performance art e a dança contemporânea para dentro da Academia, fornecendo-Ihes um estatuto que ainda estão longe de possuir.

\section{Notas finais}

${ }^{1}$ Ao longo do presente artigo, utilizaremos quase sempre a designação performance art (ou o seu equivalente português arte-performance, mais utilizado no Brasil), em vez de simplesmente performance, de modo a evitar confusão com o sentido corrente de "atuação, interpretação", aplicável a diversas artes. Uma outra designação possível seria performance corporal (cf., por ex. Ribeiro, 1997).

2 Tradução livre: "A Música não pode ser melhor definida do que como irmã da Pintura (...) mas a Pintura supera e ultrapassa a Música, uma vez que não morre imediatamente após a sua criação, como acontece com a sua desafortunada irmã; pelo contrário, ela permanece em existência e assim se nos mostra como algo vivo, embora de facto esteja confinada a uma superfície."

${ }^{3}$ A expressão "artes do desenho" é de Giorgio Vasari, autor das Vidas dos mais Excelentes Pintores, Escultores e Arquitetos (Florença, 1550; 2. ${ }^{a}$ ed. alargada 1568), unanimemente consideradas como o modelo fundador da história de arte. Nas artes do tempo incluem-se, naturalmente, as artes do corpo embora, à época, não fossem designadas assim.

4 "A vida é breve, mas a arte é perene"; atribuído ao médico grego Hipócrates.

${ }^{5}$ Por exemplo na llíada (VI, 359) de Homero; cf. também Dante (Inferno, XV, 85).

${ }^{6}$ Cf. Vasari, Vidas... (Florença, 1568).

\section{Referências bibliográficas}

Aristóteles. (1992), Poética (trad. Eudoro de Sousa) Lisboa: Imprensa Nacional - Casa da Moeda, 3. ${ }^{\text {a }}$ ed.

Benjamin, W. (1992), Sobre Arte, Técnica, Linguagem e Política, Lisboa: Relógio d'Água

Bourcier, P. (2006), História da Dança no Ocidente, São Paulo: Martins Fontes.

Carchia, G. e D’Angelo, P. (eds.) (2009), Dicionário de Estética, Lisboa: Edições 70.

Castiglione, B. (1987 [1528]), The Book of the Courtier (trad. Georges Bull), Harmondsworth: Penguin Books.

Ciotti, N. (2011), "Aprendendo e ensinando através da performance", in Oliveira, A.W. (org.), A Performance Ensaiada, Fortaleza: LICCA /Expressão Gráfica e Editora, pp. 29-41.

Cohen, R. (2002), Performance como linguagem, São Paulo: Editora Perspectiva.

Fabião, E. (2011), "Performance e precariedade", in Oliveira, A.W. (org.), A Performance Ensaiada, Fortaleza: LICCA /Expressão Gráfica e Editora, pp. 63-85.

Fetterman, W. (1999), "Merce Cunningham and John Cage: Choreographic Cross-currents", Contemporary Music Review, vol.18, Part 1, pp. 121-142.

Fischer-Lichte, E. (2019), Estética do Performativo, Lisboa: Orfeu Negro

Goldberg, R., (2012), A arte da performance do futuro ao presente, Lisboa: Orfeu Negro.

Gombrich, E. H. (1964), "Moment and Movement in Art", Journal of the Warburg and Courtauld Institutes, vol. 27, pp. 293-306.

Holanda, F. (1983 [1548]), Da Pintura Antiga, Lisboa: Imprensa Nacional -Casa da Moeda.

Huisman, D. (1983), A Estética, Lisboa: Edições 70.

Kunst, B. (2011), "Dance and Work: The Aesthetic and Political Potential of Dance", in Klein, G., Noeth, S., The Performance of Worldmaking in Dance and Choreography, Bielefeld: Transcript Verlag, pp. 47-59.

Laban, R. (1978). Domínio do movimento. São Paulo, BR: Summus Editorial.

Lepecki, A. (2011), "O corpo como arquivo vontade 
de reencenar e pós-vida de obras de dança", in Oliveira, A.W. (org.), A Performance Ensaiada, Fortaleza: LICCA / Expressão Gráfica e Editora, pp. 103-139.

Miller, J. (1986), Subsequent Performances, Londres: Faber and Faber

Rein, A. (2011), "Flee(t)ing Dances! Initiatives for the Preservation and Communication of Intangible World Heritage in Museums" in Klein, G., Noeth, S., The Performance of Worldmaking in Dance and Choreography, Bielefeld: Transcript Verlag.

Ribeiro, A. P. (1997), Corpo a Corpo: possibilidades e limites da crítica, Lisboa: Ed. Cosmos

Richter, I. A. (ed.) (1980), The Notebooks of Leonardo da Vinci, Oxford: Oxford University Press

Santos, M. A. Q. (2019), Dança em formação: um estudo comparativo entre Portugal e Brasil. Dissertação de mestrado. Aveiro: Universidade de Aveiro

Schechner, R. (2013), "What is Performance Studies?", Rupkatha Journal On Interdisciplinary Studies in Humanities, vol. 5, n. 2, pp. 2-11.

Setenta, J. S. (2011), "Dança e/em Performance o fazer-dizer de corpos na contemporaneidade", in Oliveira, A.W. (org.), A Performance Ensaiada, Fortaleza: LICCA / Expressão Gráfica e Editora, pp. 191-200.

Siqueira, D. C. O. (2006) Corpo, comunicação e cultura: a dança contemporânea em cena. Campinas: Autores Associados.

\section{Webgrafia}

Dicionário Houaiss da Língua Portuguesa. Rio de Janeiro: Ed. Objetiva, 2001 (versão Intranet), disponível em: http:// houaiss.web.ua.pt/cgi-bin/houaissnetb.dll/frame

Dicionário Priberam da Língua Portuguesa (on line), disponivel em: https://dicionario.priberam.org/

Merce Cunningham Trust. Disponível em: https://www. mercecunningham.org/

Robert Wilson \& Philip Glass's Einstein on the Beach. Disponível em: https://www.youtube.com watch?v=DOnNJgTZIYo

Robert Wilson. Disponível em: http://www.robertwilson.com/

Trisha Brown Dance Company. Disponível em: http://www. trishabrowncompany.org/

\section{Filmografia}

Pina. 2011. De Wim Wenders. França/Alemanha: Mongrel Media.

Este trabalho é financiado por fundos nacionais através da FCT - Fundação para a Ciência e a Tecnologia, I.P., no âmbito do projeto UIDB/04057/2020.

This work is financed by national funds through the FCT Fundação para a Ciência e a Tecnologia, I.P., in the ambit of the project UIDB/04057/2020. 